\title{
INVESTIGATION OF THE N-TERMINAL CODING REGION OF MUC7 ALTERATIONS IN DENTISTRY STUDENTS WITH AND WITHOUT CARIES
}

\author{
Koç Öztürk L ${ }^{1}$, Yarat A ${ }^{1}$, Akyuz $\mathrm{S}^{3}$, Furuncuoglu $\mathrm{H}^{3}$, Ulucan $\mathrm{K}^{1,2, *}$
}

\begin{abstract}
*Corresponding Author: Dr. Korkut Ulucan, Department of Molecular Biology and Genetics, Faculty of Engineering and Natural Sciences, Üsküdar University, Haluk Turksoy Sok. No. 14, Üsküdar, İstanbul 34662, Turkey. Tel: +90-216-400-2222-2409. Fax: +90-216-400-2222; Mobile: +90-532-692-1922.

E-Mail: korkutulucan@hotmail.com
\end{abstract}

\begin{abstract}
Human low-molecular weight salivary mucin (MUC7) is a small, secreted glycoprotein coded by MUC7. In the oral cavity, they inhibit the colonization of oral bacteria, including cariogenic ones, by masking their surface adhesions, thus helping saliva to avoid dental caries. The N-terminal domain is important for low-molecular weight (MG2) mucins to contact with oral microorganisms. In this study, we aimed to identify the N-terminal coding region of the MUC7 gene between individuals with and without caries. Forty-four healthy dental students were enrolled in this study; 24 of them were classified to have caries [decayed, missing, filled-teeth (DMFT) $=5.6$ ] according to the World Health Organization (WHO) criteria, and 20 of them were caries-free (DMFT $=0)$. Simplified oral hygiene index (OHI-S) and gingival index (GI) were used to determine the oral hygiene and gingival conditions. Total protein levels and salivary total protein levels and salivary buffer capacity (SBC) were determined by Lowry and Ericsson methods. DNA was extracted from peripheral blood cells of all the participants and genotyping was carried out by a polymerase chain reaction (PCR)-sequencing method. No
\end{abstract}

\footnotetext{
${ }^{1}$ Department of Basic Medical Sciences, Faculty of Dentistry, Marmara University, İstanbul, Turkey

2 Department of Molecular Biology and Genetics, Faculty of Engineering and Natural Sciences, Üsküdar University, İstanbul, Turkey

${ }^{3}$ Department of Clinical Sciences, Faculty of Dentristry, Marmara University, İstanbul, Turkey
}

statistical differences were found between two groups in the terms of salivary parameters, oral hygiene and gingival conditions. We detected one common single nucleotide polymorphism (SNP) that leads to a change of asparagine to lysine at codon 80 . This substitution was found in 29.0 and $40.0 \%$, respectively, of the groups with and without caries. No other sequence variations were detected. The SNP found in this study may be a specific polymorphism affecting the Turkish population. Further studies with extended numbers are necessary in order to clarify this finding.

Keywords: Dental caries, oral hygine indicis, low molecular weight salivar mucin (MUC7).

\section{INTRODUCTION}

Dental caries is one of the most prevalent human infectious diseases affecting life style and genetic factors. The skewed distribution of caries in the Western populations and its weak association with traditional life style factors, e.g., sugar intake and oral hygiene, suggest genetic components in caries development. Early studies have shown that there were large individual differences in caries development in spite of similar exposures to sugars [1].

Mucins are vital components of the mucous layers covering the epithelial surfaces of the human body. In the oral cavity, mucins are secreted by submandibular and sublingual glands, and various minor salivary glands, but not by the parotid glands. Mucins constitute the third most abundant group of proteins in saliva and form various complexes with other sali- 
vary proteins, thereby modulating their activities. Two structurally distinct mucins have been identified in human saliva: high-molecular weight (MG1) and the low-molecular weight (MG2) mucins [2].

The human MUC7 gene encodes a relatively small mucin glycoprotein, MUC7 (125 kD). It is also known as MG2. Low-molecular weight mucin is secreted mainly by human sublingual and submandibular glands. As a salivary glycoprotein, it is involved in mastication, speech, swallowing and lubrication of the oral cavity [3]. Early studies indicate that MG2 takes part in the human salivary nonimmune defense system and interacts with oral microorganisms, and it also appears that MG2 plays a role in mediating interactions between neutrophils and bacteria. The ability of MG2 to self-associate, creating larger assemblies through non covalent bonds, has also been proposed to contribute to the agglutinating and eliminating properties of the mucin [4].

The exploitation of mucin molecules for diagnostics is gaining increasing interest in a variety of disease conditions [3]. A recent study has suggested that genetic polymorphisms, which can alter mucin gene expression, have been associated with mucinrelated diseases [5]. While no studies have been performed on the MG2 polymorphism for dental caries, the potential of these molecules about dental caries cannot be ignored and will likely be subjected to further exploration.

To date, the relationship between the MUC7 $\mathrm{N}$-terminal coding region and dental caries is still unclear. Thus, in the present study, we aim to identify the effects of N-terminal coding region $M U C 7$ polymorphisms and dental caries.

\section{MATERIALS AND METHODS}

Study Groups. The study included 24 dental students with caries aged between 18 to 23 years (mean age $20.2 \pm 1.2$ ) and 20 dental students without caries aged between 19 to 26 years (mean age $21.95 \pm 2.2$ ). Forty-four healthy dentistry students were enrolled in this study, 24 of them (aged between 18 to 23 years, mean age $20.2 \pm 1.2$ ) were classified to have carries [decayed, missing, filled-teeth $(\mathrm{DMFT})=5.6]$ according to the World Health Organization (WHO) criteria, and 20 of them (aged between 19 to 26, mean age $21.95 \pm 2.2$ ) were caries- free $(\mathrm{DMFT}=0)$. Inclusion criteria for subjects with caries and without caries were as follows; no oral complains, good oral hygiene, absence of smoking and drinking habits, no systemic diseases, no drug abuse. Exclusion criteria was unwillingness to participate in the study. The subjects signed an informed consent form to participate in this study.

Clinical Examination. One experienced dentist examined all subjects for their adherence to inclusion criteria. The WHO criteria were used for DMFT [6]. The oral hygiene and gingival status were assessed using the simplified oral hygiene index (OHI-S) and gingival index (GI) [7]. A structured questionnaire was used to collect data on oral hygiene habits (frequency of tooth brushing, use of dental floss), professional counseling on oral health and hygiene, and the presence of gingival bleeding. All subjects had good oral health and had regular dental care.

Collection of Saliva. Fasting unstimulated whole saliva samples were collected at the same time of day (between 08:30 and 11:00 am) for a 1-week period by the same researcher in all cases. Before saliva collection, the mouth was rinsed with distilled water. Subsequently, saliva was allowed to accumulate on the floor of the mouth and the subjects were instructed to spit into the test tubes. During the saliva collection, the participants stayed in a relaxed position with their heads bent forward. Each saliva collection period was 10 minutes long. Immediately after collection, saliva volume was measured and then salivary flow rate calculated as $\mathrm{mL} / \mathrm{min}$. Saliva samples were stored at $-20{ }^{\circ} \mathrm{C}$ until used.

Salivary Analysis. The temperature of the saliva samples was raised from $-24{ }^{\circ} \mathrm{C}$ to $4{ }^{\circ} \mathrm{C}$ and kept for an hour. After thawing, they were centrifuged and supernatants were used for salivary analysis. Total protein level was determined by the method of Lowry et al. [8]. Bovine serum albumin (BSA) was used as a standard, and absorbance evaluated at $500 \mathrm{~nm}$. Total protein level was expressed as $\mathrm{mg} \%$. Salivary $\mathrm{pH}$ was directly measured with $\mathrm{pH}$ paper $(\mathrm{pH}$ indikatörpapier, Merck Neutrolit-5.5-9.0; Merck, Darmstadt, Germany). Salivary buffer capacity (SBC) was measured by Ericsson's method, modified by Menteş et al. [9]. Two hundred $\mu \mathrm{L}$ of saliva was mixed with $600 \mu \mathrm{L} \mathrm{HCl}$ $(0.0033 \mathrm{M})$. After $10 \mathrm{~min}$., the $\mathrm{pH}$ of the mixture was immediately measured with $\mathrm{pH}$ paper $(\mathrm{pH}$ indikatörpapier, Merck Neutrolit-5.5-9.0; Merck). Based on the color change of the indicator paper strip, the $\mathrm{pH}$ was assessed in comparison with a color chart. The corresponding value is taken as the $\mathrm{pH}$ of the mixture. 
DNA Genotyping. The Marmara University Ethics Committee approved the study protocol, and written informed consent was obtained from all participants. DNA was extracted from peripheral blood cells by using High Pure polymerase chain reaction (PCR) Template Preparation Kit (Roche Diagnostics Deutschland GmbH, Mannheim, Germany) according to the manufacturer's instructions. Isolated DNA samples were kept at $-20{ }^{\circ} \mathrm{C}$ if not studied on the same day. The $M U C 7 \mathrm{~N}$-terminal coding region was amplified using specific primers: 5'-GAA GGT CGA GAAAGG GAT CAT-3' and 5'-GTC TTG TGG AGC TGG GGA AT-3'. Polymerase chain reaction was performed in a final volume of $50 \mu \mathrm{L}$ containing 2-10 ng DNA, $200 \mathrm{mM}$ of each deoxynucleotide triphosphate (dNTP), $1.5 \mathrm{mM} \mathrm{MgCl}, 10 \mathrm{mM}$ Tris/ $\mathrm{HCl}, \mathrm{pH} 8.3,50 \mathrm{mM} \mathrm{KCl}, 10$ pmole of each primer, and $0.1 \mathrm{U}$ Taq polymerase. Thermocycle settings consisted of a denaturation step at $94{ }^{\circ} \mathrm{C}$ for $3 \mathrm{~min}$., followed by 35 cycles at $94{ }^{\circ} \mathrm{C}$ for 60 seconds, $62{ }^{\circ} \mathrm{C}$ for 60 seconds, and $72{ }^{\circ} \mathrm{C}$ for 60 seconds and a final extension at $72{ }^{\circ} \mathrm{C}$ for $5 \mathrm{~min}$. The $199 \mathrm{bp}$ amplicons were sequenced with ABI PRISM ${ }^{\mathrm{TM}} 3100$ Genetic Analyzer using DYNemic ET Terminator Cycle Sequencing Kit (GE Healthcare Life Sciences, Little Chalfont, Buck-inghamshire, UK).

Statistical Analysis. The significance in the statistical analyses between groups was assessed using the $\chi^{2}$ test [Statistical Package for the Social Sciences (SPSS) 10.0 for Windows; SPSS Inc., Chicago, IL, USA]. Relationships yielding $p$ values less than 0.05 were considered to be significant.

\section{RESULTS}

Simplified oral hygiene index and GI were not significantly different between the two groups. Salivary $\mathrm{pH}$, flow rate, buffering capacity and total protein levels were also not significantly different between the young adults with caries (DMFT $=5.62)$ and without caries $(\mathrm{DMFT}=0)(p>0.05)$. Table 1 lists the values of these markers.

No new variants were observed in 44 subjects in the N-terminal coding region of the $M U C 7$ gene. When we compared the two groups, we detected no significant difference. Moreover, we detected one common single nucleotide polymorphism (SNP), namely, a $\mathrm{C}>\mathrm{G}$ transversion leading to an asparagine to lysine change at codon 80 (N80K) (Figure 1). This substitution was found to be 29.0 and $40.0 \%$, respectively, in the groups with and without caries.

\section{DISCUSSION}

Mucins coat the gastrointestinal, genito-urinal and respiratory tracts, as well as the oral cavity. In the oral cavity, they have a variety of functions such as lubricating and protecting the oral cavity and providing a nonspecific immune defense [10].

In our cohort, OHI-S, GI, salivary $\mathrm{pH}$, flow rate, buffering capacity and total protein levels were not significantly different between the two groups. These parameters have important effects on oral hygiene, and also for dental caries. But in our study cohort, all of these parameters did not affect dental caries formation.

Low-molecular weight mucin contains 377 amino acids. The first 20 of these are located in the $\mathrm{N}$-terminal domain and are very hydrophobic. It contains a central part, made of six tandem repeats of 23 amino acids that are rich in proline and hydroxylated amino acids, and having approximately 90-100 O-linked chains. A histatin-like domain with a leucine-zipper segment, followed by a moderately glycosylated region, constitute the N-terminal domain; a heavily glycosylated domain, and a second

Table 1. Mean levels of all parameters, and $p$ values for the examined groups.

\begin{tabular}{|l|c|c|c|}
\hline Parameters & Group With No Caries $(\boldsymbol{n = 2 0})$ & Group With Caries $(\boldsymbol{n}=\mathbf{2 4})$ & $\boldsymbol{p}$ Value \\
\hline Simplified oral hygiene index & $0.14 \pm 0.008$ & $0.15 \pm 0.011$ & 0.605 \\
\hline Gingival index & $0.017 \pm 0.008$ & $0.02 \pm 0.009$ & 0.507 \\
\hline $\mathrm{pH}$ & $7.02 \pm 0.41$ & $7.17 \pm 0.35$ & 0.292 \\
\hline Salivary flow rate (mL/min.) & $0.48 \pm 0.22$ & $0.52 \pm 0.24$ & 0.577 \\
\hline Salivary buffering capacity & $1.63 \pm 0.32$ & $1.50 \pm 0.29$ & 0.174 \\
\hline Salivary total protein (mg/dL) & $131.00 \pm 48.00$ & $132.00 \pm 49.00$ & 0.871 \\
\hline
\end{tabular}

${ }^{a}$ Results are presented as mean \pm SD (standard deviation). 


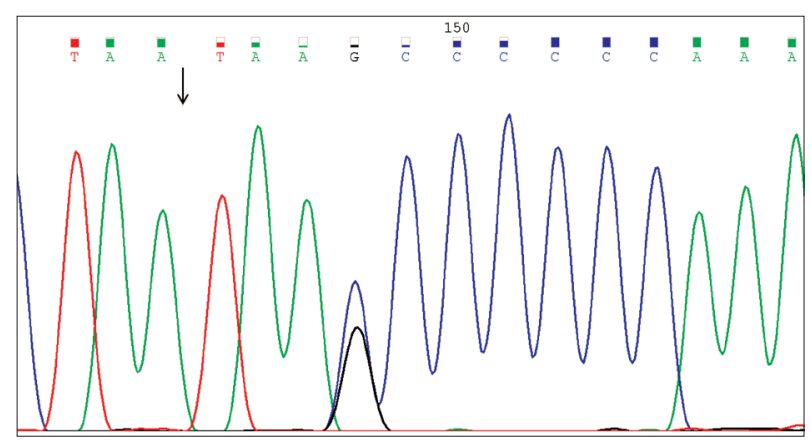

Figure 1. Chromatogram analysis showing the polymorphic site within the $M U C 7$ gene. The arrow indicate the SNP site. A C $>\mathrm{G}$ transversion at codon 80 leads to an asparagine to lysine change in the protein.

leucine-zipper segment for the C-terminal extremity. The distal regions of MUC7 do not exhibit any cysteine-rich domains, only two cysteine residues are present towards its N-terminal end. So far, MG2 has no sequence homology with any other mucins. The N-terminal region of the protein binds Streptococcus mutans (S. mutans). It also exhibits a candidacidal activity and, after cleavage, a subdomain of this region is microbicidal against a periodontal pathogen, Actinobacillus actinomycetemcomitans. Furthermore, a MUC7 20-mer displays potent killing activity against a variety of fungi and both gram-positive and gramnegative bacteria $[4,11,12]$. The two cysteine residues located in the N-terminal region of MUC7 seem to be directly implicated in these activities [12].

Low-molecular weight mucin has been reported to interact with several strains of streptococci by promoting their agglutination [13]. The N-terminal region of MG2 has a broad-spectrum fungicidal and bactericidal activity in vitro $[14,15]$. Low-molecular weight mucin peptides derived from the $\mathrm{N}$-terminal of MG2 are the cationic anti-microbial peptides derived from the human low molecular weight salivary mucin, a component of innate immunity (the first-line of the host defense system against pathogens). Lowmolecular weight mucin (357 amino acid residues in saliva), protects the oral cavity from microbial infections through more general protective mechanisms rather than the direct killing of microorganisms [16].

It was shown that a $20 \mathrm{kDa}$ MG2 fragment, containing the $\mathrm{N}$-terminal region, was present in the saliva and suggested that cleavage of MG2 in vivo may lead to the fragments with microbicidal properties [17]. The MG2 20-mer, sub-domain of N- terminal domain, has been shown to be able to cross the fungal cell membrane and accumulate inside the cells, suggesting a possibility that MG2 peptides may also exert killing activity against $S$. mutans [18]. In some conditions, rather than killing the bacteria directly, they disturb cariogenic and periodontal pathogen activity by interacting with them, binding the bacteria via their cysteine residues within their $\mathrm{N}$-terminal domain $[19,20]$. The peptides derived from the $\mathrm{N}$-terminal region of MG2 present somewhat preferential antimicrobial activity against $S$. mutans. They also have an effect on in vitro formation and reduction of the preformed S. mutans biofilm [15]. We did not detect any statistically significant polymorphisms between caries and caries-free groups in the present study. There was one common SNP, affecting the amino acid at position 80, changing the natural amino acid asparagine to lysine. This SNP seemed to have no effect on dental caries in individuals, but seems to be an important polymorphism in the examined Turkish subjects.

In conclusion, the SNP detected in this study may be a specific polymorphism effecting the Turkish population. Further studies with a larger number of individuals are necessary in order to clarify our findings.

Declaration of Interest. The authors report no conflicts of interest. The authors alone are responsible for the content and writing of this article.

\section{REFERENCES}

1. Jonasson A, Eriksson C, Jenkinson HF, Källestål C, Johansson I, Strömberg N. Innate immunity glycoprotein gp-340 variants may modulate human susceptibility to dental caries. BMC Infect Dis. 2007; 7: 57. doi: 10.1186/ 1471-2334-7-57.

2. Oppenheim FG, Salih E, Siqueira WL, Zhang W, Helmerhorst EJ. Salivary proteome and its genetic poly-morphisms, Ann NY Acad Sci USA. 2007; 1098: 22-50.

3. Li S, Intini G, Bobek LA. Modulation of MUC7 mucin expression by exogenous factors in airway cells in vitro and in vivo. Am J Respir Cell Mol Biol. 2006; 35(1): 95-102.

4. Sonesson M, Wickström C, Kinnby B, Ericson D, Matsson L. Mucins MUC5B and MUC7 in minor salivary gland secretion of children and adults. Arch Oral Biol. 2008; 53(6): 523-527. 
5. Silva DG, Stevens RH, Macedo JMB, Hirata $\mathrm{R}$, Pinto AC, Alves LM, et al. Higher levels of salivary MUC5B and MUC7 in individuals with gastric diseases who harbor Helicobacter pylori. Arch Oral Biol. 2009; 54(1): 86-90.

6. World Health Organization: Oral Health Surveys, Basic Methods, 3rd ed., Geneva, 1987.

7. Rose LF, Mealey BL, Genco RJ, Cohen W. Periodontics; medicine, surgery and implants. In: Ronderos M, Michalowicz BS, Eds. Epidemiology of Periodental Diseases and Risk Factors. St. Louis, MO, USA: Elsevier Mosby; 2004: 32-68.

8. Lowry $\mathrm{OH}$, Rosebrough AL, Farr AL, Randall RJ. Protein measurements with Folin-Phenol reagents. J Biol Chem. 1951; 193(1): 265-275.

9. Menteş A, Kargül B, Tanboğa I. Relationship between unstimulated and stimulated salivary flow rate, $\mathrm{pH}$, buffering capacity and caries index in a groups of young adults. AÜ Dis Hek Fak Derg. 1995; 22(1): 27-34.

10. Mahajan M, Alam M, Saraswat M, Singh TP, Yadav S. Hydrodynamic behavior of Human Whole Salivary Mucin: A Dynamic Light Scattering study. International Journal of Life Sciences and Technology. 2008; 1(1): 1-8.

11. Roussel P, Delmotte P. The diversity of epithelial secreted mucins. Curr Org Chem. 2004; 8(5): 413-437.

12. Moniaux N, Escande F, Porchet F, Aubert JP, Batral SK. Structural organization and classification of the human mucin genes. Front Biosci. 2001; 6: D1192-D2106.

13. Baughan LW, Robertello FJ, Sarrett DC, Denny PA, Denny PC. Salivary mucins as related to oral Streptococcus mutans in elderly people. Oral Microbiol Immunol. 2000; 15(1): 10-14.
14. Situ H, Wei GX, Smith CJ, Mashhoon S, Bobek LA. Human salivary MUC7 mucin peptides: Effect of size, charge and cysteine residues on antifungal activity. Biochem J. 2003; 375(Pt 1): 175-182.

15. Wei GX, Campagna AN, Bobek LA. Effect of MUC7 peptides on the growth of bacteria and on Streptococcus mutans biofilm. J Antimicrob Chemother. 2006; 57(6): 1100-1109.

16. Wei GX, Campagna AN, Bobek LA. Factors affecting antimicrobial activity of MUC7 12-mer, a human salivary mucin-derived peptide. Ann Clin Microbiol Antimicrob. 2007; 6: 14. doi: 10.1186/1476-0711-6-14.

17. Gururaja TL, Levine JH, Tran DT, Naganagowda GA, Ramalingam K, Ramasubbu N, et al. Candidacidal activity prompted by N-terminus histatin-like domain of human salivary mucin (MUC7)1. Biochim Biophys Acta. 1999; 1431(1): 107-119.

18. Groenink J, Walgreen-Weterings E, Nazmi K, Bolscher JG, Veerman EC, van Winkelhoff AJ, et al. Salivary lactoferrin and low-Mr mucin MG2 in actinobacillus actinomycetemcomitans-associated periodontitis. J Clin Periodontol. 1999; 26(5): 269-275.

19. Schenkels LCPM, Gururaja TL, Levine MJ. Salivary mucins: Their role in oral mucosal barrier function and drug delivery. In: Rathbone MJ, Ed. Oral Mucosal Drug Delivery. New York, NY, USA: Marcel Dekker Inc. 1996:191-220.

20. Satyanarayana J, Situ H, Narasimhamurthy S, Bhayani N, Bobek LA, Levine MJ. Divergent solid-phase synthesis and candidacidal activity of MUC7 D1, a 51-residue histidine-rich N-terminal domain of human salivary mucin MUC7. J Pept Res. 2000; 56(5): 275-282. 
